\title{
How large is the lung recruitability in early acute respiratory distress syndrome: a prospective case series of patients monitored by computed tomography
}

Gustavo FJ de Matos', Fabiana Stanzani', Rogerio H Passos', Mauricio F Fontana', Renata Albaladejo', Raquel E Caserta', Durval CB Santos², João Batista Borges ${ }^{3,4}$, Marcelo BP Amato ${ }^{3}$ and Carmen SV Barbas ${ }^{1,3^{*}}$

\begin{abstract}
Introduction: The benefits of higher positive end expiratory pressure (PEEP) in patients with acute respiratory distress syndrome (ARDS) have been modest, but few studies have fully tested the "open-lung hypothesis". This hypothesis states that most of the collapsed lung tissue observed in ARDS can be reversed at an acceptable clinical cost, potentially resulting in better lung protection, but requiring more intensive maneuvers. The short-/ middle-term efficacy of a maximum recruitment strategy (MRS) was recently described in a small physiological study. The present study extends those results, describing a case-series of non-selected patients with early, severe ARDS submitted to MRS and followed until hospital discharge or death.
\end{abstract}

Methods: MRS guided by thoracic computed tomography $(\mathrm{CT})$ included two parts: a recruitment phase to calculate opening pressures (incremental steps under pressure-controlled ventilation up to maximum inspiratory pressures of $60 \mathrm{cmH}_{2} \mathrm{O}$, at constant driving-pressures of $15 \mathrm{cmH}_{2} \mathrm{O}$ ); and a PEEP titration phase (decremental PEEP steps from 25 to $10 \mathrm{cmH}_{2} \mathrm{O}$ ) used to estimate the minimum PEEP to keep lungs open. During all steps, we calculated the size of the non-aerated $(-100$ to $+100 \mathrm{HU})$ compartment and the recruitability of the lungs (the percent mass of collapsed tissue re-aerated from baseline to maximum PEEP).

Results: A total of 51 severe ARDS patients, with a mean age of 50.7 years (84\% primary ARDS) was studied. The opening plateau-pressure was $59.6\left( \pm 5.9 \mathrm{cmH}_{2} \mathrm{O}\right)$, and the mean PEEP titrated after MRS was $24.6\left( \pm 2.9 \mathrm{cmH}_{2} \mathrm{O}\right)$. Mean $\mathrm{PaO}_{2} / \mathrm{FiO}_{2}$ ratio increased from $125( \pm 43)$ to $300( \pm 103 ; P<0.0001)$ after MRS and was sustained above 300 throughout seven days. Non-aerated parenchyma decreased significantly from 53.6\% (interquartile range (IQR): 42.5 to 62.4$)$ to $12.7 \%$ (IQR: 4.9 to 24.2$)(P<0.0001)$ after MRS. The potentially recruitable lung was estimated at $45 \%$ (IQR: 25 to 53). We did not observe major barotrauma or significant clinical complications associated with the maneuver.

Conclusions: MRS could efficiently reverse hypoxemia and most of the collapsed lung tissue during the course of ARDS, compatible with a high lung recruitability in non-selected patients with early, severe ARDS. This strategy should be tested in a prospective randomized clinical trial.

* Correspondence: carmen.barbas@gmail.com

${ }^{1}$ Adult ICU Hospital Israelita Albert Einstein, São Paulo, 05652-000, Brazil

Full list of author information is available at the end of the article 


\section{Introduction}

Severe ARDS still has a very high mortality rate despite all advances in critical care [1]. Ventilator Induced Lung Injury (VILI) plays a major role in the poor prognosis of such patients, as demonstrated by extensive experimental and clinical evidence [2-10]. But there is no consensus yet on the least harmful mechanical ventilation to be individually applied at bedside [11-18]. Although most studies indicate that reducing inspiratory pressures and tidal volumes is generally beneficial, many uncertainties remain about the actual impact of the PEEP selection. Abundant physiological data suggest that the combination of recruitment maneuvers and individual PEEP titration is essential to optimize the effects of PEEP, but the proof of such benefits in humans is not yet conclusive [11,12,19-22].

Recently, three large clinical trials [13-15], including Acute Lung injury/ARDS patients ventilated with low tidal-volume, have compared different PEEP strategies (high vs. low), but none of them could show a significant difference in mortality. A recent meta-analysis has pooled those trials [23], revealing some combined benefit of the high PEEP strategy; still, the survival benefit was modest and limited to the subgroup of ARDS patients. Conceptually, one could argue that none of the "high-PEEP" strategies was designed to test the "openlung hypothesis" postulated by Lachmann [24-27], that is, the hypothesis that most of the collapsed lung tissue observed in early ARDS can be reversed at an acceptable clinical cost, potentially resulting in better lung protection. According to a recent study by Borges and colleagues $[22,28]$, a straight test of the "open-lung hypothesis" would certainly require more aggressive recruiting maneuvers in association with individualized, decremental PEEP titration. Thus, one can speculate that the limited results reported above were related to sub-optimal ventilatory strategy.

Although the study by Borges and colleagues [22] provided a good description of the physiological principles of the Maximum Recruitment Strategy (MRS), there is still a lack of information regarding the long term management, side effects, and generality of such findings in a non-selected population. In fact, a recent study by Gattinoni and colleagues [29] with 68 ALI/ARDS patients submitted to recruitment strategies, all under close monitoring by computed tomography (CT), has cast doubts about the feasibility of the "open-lung" strategy, since the recruitability of the lungs reported in this study varied too much among patients, amounting to less than $15 \%$ in most patients.

Thus, the objective of this study was to describe the feasibility and long term impact of the MRS applied in a case-series of non-selected patients with severe ARDS.
All patients were closely monitored by multi-slice CT during the implemented strategy. Since the maneuver was individualized and applied in a more intensive fashion than in previous studies, we tried also to provide a more precise, bedside estimation of lung recruitability in a general population of patients with early ARDS.

\section{Materials and methods \\ Patients}

This study was conducted in a general medical/surgical ICU with 42 beds at the Albert Einstein Hospital, São Paulo, Brazil. From January 2003 to June 2009, 69 consecutive patients were screened for early and severe ARDS, according to the inclusion criteria depicted below. The 51 patients who did not meet any exclusion criteria were studied. The hospital ethical committee granted approval to this study and informed consent was obtained from patients' relatives.

\section{Early and severe ARDS inclusion criteria}

In addition to the ARDS definition of the AmericanEuropean Consensus Conference 1994, three additional inclusion criteria were required: a) less than 72 hours onset; b) age between 14 and 80 years, and c) $\mathrm{PaO}_{2} /$ $\mathrm{FIO}_{2}<200$, obtained with PEEP $\geq 10 \mathrm{cmH}_{2} \mathrm{O}, \mathrm{FIO}_{2}$ of 1.0 and pressure-controlled ventilation with driving pressure set at $15 \mathrm{cmH}_{2} \mathrm{O}$.

\section{Exclusion criteria}

Exclusion criteria for this study includes cardiac arrest in the last 48 hours; persistent hemodynamic instability (defined as: mean arterial pressure $<70 \mathrm{mmHg}$, central venous saturation $\left(\mathrm{ScvO}_{2}<70 \%\right)$, despite adequate preload optimization with intravenous fluids and vasopressors); formal contraindication of hypercapnia (for example, acute coronary disease, cardiac arrhythmias, intracranial hypertension); active bronchopleural fistula; incapacity to perform CT scan due to excess body weight (>180 kg) or size (abdominal circumference > $200 \mathrm{~cm}$ ); do not resuscitate orders; pregnancy; and denial from the family or assistant physician.

\section{Baseline mechanical ventilation settings}

Baseline arterial blood gas was drawn with a minimum PEEP of $10 \mathrm{cmH}_{2} \mathrm{O}$ (enough to keep $\mathrm{SpO}_{2}>90 \%$ ), pressure-controlled ventilation, driving-pressure of 15 $\mathrm{cmH}_{2} \mathrm{O}$, respiratory-rate of 15 to 20 breaths/minute, inspired oxygen-fraction $\left(\mathrm{FIO}_{2}\right)=1.0$.

\section{Transportation to CT facility}

Patients were deeply sedated (midazolam and fentanyl) and paralyzed (cisatracurium). All patients were monitored with central venous (Arrow CV-17702-E-USA) 
and arterial (Arrow RA-04220-W-USA) lines, and submitted to a preload optimization protocol targeting pulse-pressure variations less than 13\% [30-32] and $\mathrm{ScvO}_{2}$ greater than $70 \%$. Patients were only transported after stabilization with fixed doses of vasopressors. A Servo 900c ventilator (Maquet, Solna, Sweden), equipped with a long term external battery, was used during transportation and CT scanning.

\section{Maximum Recruitment Strategy (MRS)}

All patients underwent MRS guided by thoracic CT scan as depicted in Figure 1. MRS consisted of two-minute steps of tidal ventilation with pressure-controlled ventilation, fixed driving-pressure $=15 \mathrm{cmH}_{2} \mathrm{O}$, a respiratory-rate of 10 to 15 breaths/minute, an inspiratory: expiratory ratio of 1:1 and stepwise increments in PEEP levels from 10 to $45 \mathrm{cmH}_{2} \mathrm{O}$ (recruitment-phase). Then, PEEP was decreased from 25 to $10 \mathrm{cmH}_{2} \mathrm{O}$ (PEEP titration-phase), in steps of $5 \mathrm{cmH}_{2} \mathrm{O}$, each one lasting four minutes.
At each of the steps marked in Figure 1, CT image sequences (Mx Twin e Mx 8000- Philips Medical Systems - Eindhoven, Netherlands) from the carina to the diaphragm were acquired during an expiratory pause of 6 to 10 seconds. The approximate position of the carina was identified in each step. Lung collapse was assessed on-line (by visual inspection, for immediate clinical decision) and off-line (for quantitative measurements described below).

For on-line visual assessment of collapse, a mediastinal window with a width of $400 \mathrm{HU}$ and center at $+50 \mathrm{HU}$ was used. $\mathrm{P}_{\mathrm{OPENING}}$ was defined as the minimum inspiratory pressure needed to achieve negligible collapse, or the minimum amount of non-aerated tissue at visual inspection of thoracic $\mathrm{CT}$ at the most dependent lung regions during the recruitment phase. Afterwards, during the PEEP titration phase, $P_{\text {CLOSE }}$ was defined as the PEEP in which visual collapse started to recur. The recruitment phase could be aborted and immediately followed by the PEEP titration phase, in case of $\mathrm{P}_{\text {OPENING }}<60 \mathrm{cmH}_{2} \mathrm{O}$.

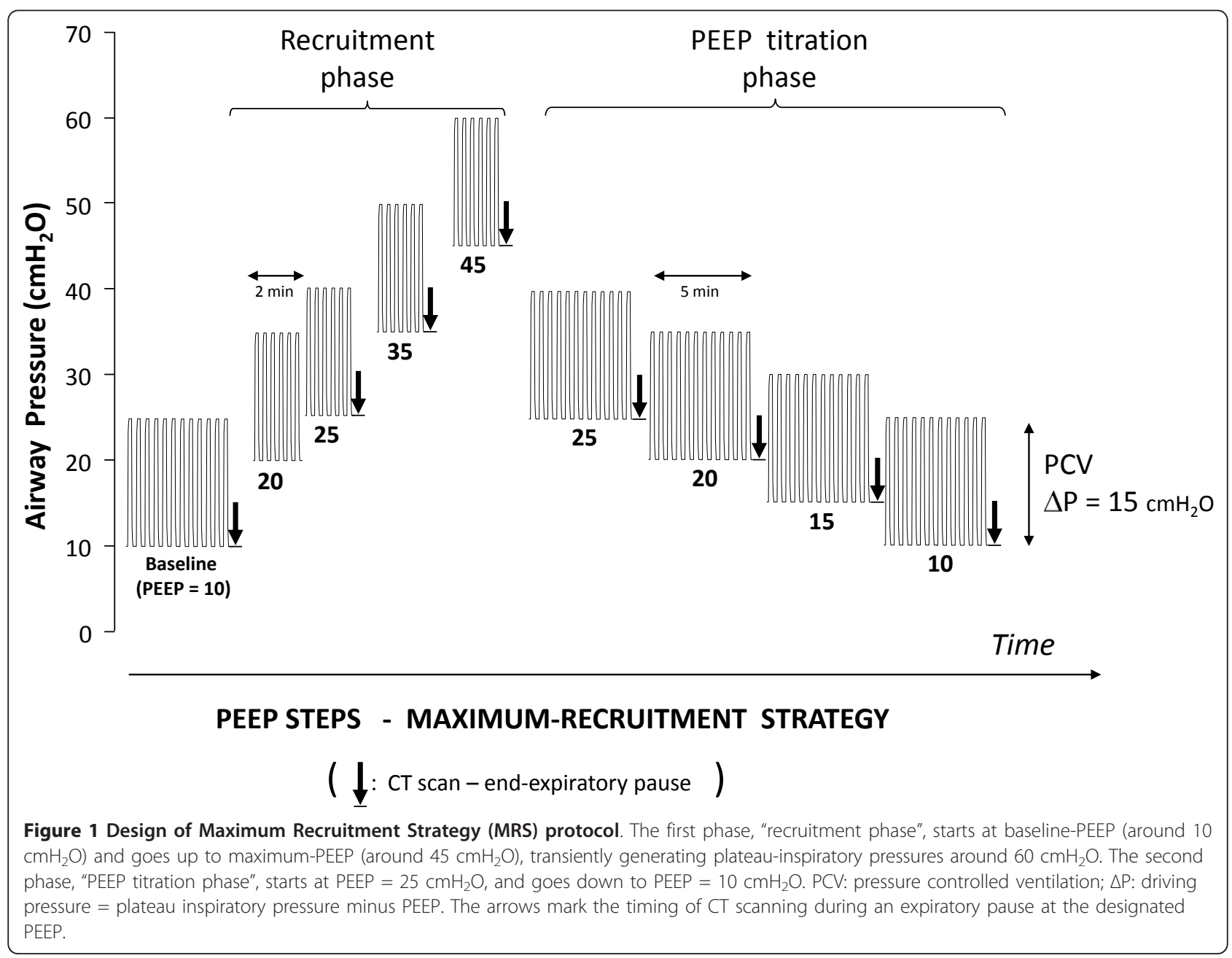


MRS was planned to be interrupted in the following situations: sustained drop, or a 30-second desaturation at arterial oxygenation $\left(\mathrm{SpO}_{2}\right)<90 \%$ after checking the adequacy of oximeter probe and finger perfusion, mean arterial pressure (MAP) $<65 \mathrm{mmHg}$, evidence of barotrauma (in CT images), or cardiac arrhythmias associated with cardiovascular collapse.

Patients were transported back to the ICU where they were submitted to a second MRS at ICU arrival, right after the ventilator change. After that, we performed no additional recruitment maneuvers, except if tidal volume decreased more than $20 \%$ at the same delta inspiratory pressure-control (considered as indicative of lung derecruitment), or in case of ventilator disconnections. The team was explicitly instructed to avoid disconnections and depressurization. Closed systems for tracheal aspiration were always used and we tried to aspirate the patients as little as possible. After ICU arrival, patients were ventilated in pressure-controlled mode, at a PEEP level above $\mathrm{P}_{\text {CLOSE }}$ (or $25 \mathrm{cmH}_{2} \mathrm{O}$ - the lower of both henceforth called titrated-PEEP), inspiratory-driving pressures $\leq 15 \mathrm{cmH}_{2} \mathrm{O}$ whenever possible and the lowest possible $\mathrm{FIO}_{2}$ to keep $\mathrm{SpO}_{2} \geq 95 \%$. Titrated-PEEP was maintained for at least 48 hours. Afterwards, PEEP was decreased in steps of $2 \mathrm{cmH}_{2} \mathrm{O}$ every 8 to 12 hours, whenever $\mathrm{PaO}_{2} / \mathrm{FIO}_{2}$ was higher than 300. If $\mathrm{PaO}_{2} / \mathrm{FIO}_{2}$ decreased to less than 300 during attempts of PEEP reduction, a new recruitment maneuver was repeated, and PEEP was restored to its previous level.

After 48 hours, and provided that PEEP could be set below $20 \mathrm{cmH}_{2} \mathrm{O}$, sedation was reduced and pressure support ventilation was started. When both, pressuresupport and PEEP levels could be reduced to $10 \mathrm{cmH}_{2} 0$, patients were extubated to non-invasive ventilation. When prolonged mechanical ventilation was anticipated, tracheostomy was performed. All patients were followed until death or discharge. Organ failure and sepsis definitions were the same as used by Villar and colleagues [12].

\section{Quantitative CT-image analysis}

Quantitative CT analysis was performed off-line, as previously described [22]. Three situations were analyzed: baseline PEEP, maximum-PEEP (during $P_{\text {OPENING }}$ detection), and titrated-PEEP. The right and left lung regions were manually segmented, conservatively avoiding partial volume artifacts from heart, chest wall and great vessels. For each region of interest (ROI) (right and left lungs) we computed the number of voxels, with its respective mass and volume within and analyzed specifically non-aerated $(-100$ to $+100 \mathrm{HU})$ density compartment.

\section{Lung recruitability analysis}

The Potentially Recruitable Lung calculation was adapted from reference [29]. Attempting to minimize radiation dose, instead of whole lung analysis, we limited CT scanning to a significant lung fraction, a thick cross-section from the carina to the diaphragm, typically encompassing 7 to $8 \mathrm{~cm}$ of the craniocaudal axis (about 8 to 10 contiguous slices), and representing the largest cross-sectional area of the lung. Accordingly, the potentially recruitable lung was calculated as a fractional mass of lung tissue within this relevant section: the mass of collapsed tissue that could be re-aerated from baseline to maximum-PEEP, divided by the total lung mass within the section.

Relative-response to the maneuver was calculated as another fractional mass, using the same numerator as above, but divided by the mass of non-aerated tissue within the section, observed at baseline-PEEP.

\section{Statistical analysis}

Quantitative variables were either presented as mean \pm standard deviation (SD), or as median with interquartile range (for non-normal distributions). ANOVA for repeated measures (after appropriate log transformations) was used to compare the amount of collapse in different phases of the protocol. The Mann-Whitney test and Multivariate Logistic regression analysis were used to check the association between clinical, CT variables and outcome. Data were analyzed with the SPSS 13.0 version $\left(\mathrm{IBM}^{\circledR}\right.$, Armonk, New York, USA). The significance level considered was $P<0.05$.

\section{Results}

Demographic and clinical characteristics of the study population are shown in Table 1. Gas exchange and

\section{Table 1 Baseline patient characteristics $(\mathbf{N}=\mathbf{5 1})$}

\begin{tabular}{cc}
\hline Age (years) & $50.7 \pm 16.5$ \\
\hline Sex (male) & $65 \%$ \\
Primary/Secondary ARDS & $84 \% / 16 \%$ \\
Pneumonia & $29(57 \%)$ \\
Aspiration gastric contents & $9(17 \%)$ \\
Sepsis & $5(10 \%)$ \\
Thoracic trauma & $2(4 \%)$ \\
TRALI & $2(4 \%)$ \\
Other & $4(8 \%)$ \\
APACHE II score & $20.2 \pm 6.2$ \\
SOFA score (day 1) & $10(7$ to 12$)$ \\
NPOF & $2(1$ to 2$)$ \\
Sepsis & $71 \%$ \\
Septic shock & $63 \%$ \\
Vasopressor & $82.3 \%$ \\
\hline CRRT & $56.8 \%$
\end{tabular}

Primary/Secondary ARDS, Primary ARDS/Secondary ARDS; TRALI, transfusion related Acute Lung Injury; NPOF, non-pulmonary organ failure; Vasopressor, percentage of patients receiving vasopressors at entry; CRRT, continuous renal replacement therapy. Data expressed as percentage (\%), mean \pm standard deviation, or median with interquartile range in brackets 
mechanical ventilation data are shown in Table 2 and hemodynamic data in Table 3

Eighteen patients were excluded because of the following reasons: hemodynamic instability judged to represent high risk for transportation (six patients), absence of informed consent (three patients), barotrauma detected before transportation (one case due to thoracic trauma and one case due to mechanical ventilation - before MRS), morbid obesity in no condition for transportation (two patients), more than $72 \mathrm{~h}$ of ARDS onset (two patients), do-not-resuscitate orders (one patient), age above 80 years (one patient) and pregnancy (one patient).

Fifty-one severe ARDS patients were included and followed, of whom $84 \%$ had primary ARDS. Communityacquired and nosocomial pneumonia represented $57 \%$ of the causes. Acute Physiology and Chronic Health Evaluation II (APACHE II) score was $20 \pm 6$, and Day-1 Sequential Organ Failure Assessment (SOFA) score was $10 \pm 3$. Non-pulmonary organ failure (NPOF) was 2 (IQR: 1 to 4 ) and $57 \%$ of patients required continuous renal replacement therapy. Seventy-one percent of the patients fulfilled sepsis criteria (89\% of whom fulfilled septic shock criteria). Eighty-two percent of the patients required norepinephrine.

\section{Opening pressures}

During MRS, Maximum PEEP was 45 (IQR: 43 to 45 ) $\mathrm{cmH}_{2} \mathrm{O}$ and Maximum Plateau Pressure was 60 (IQR: 58 to 60$) \mathrm{cmH}_{2} \mathrm{O}$. In 13 cases, opening pressures (that is, the plateau-pressures associated with massive recruitment, during visual assessment) were lower than 60 $\mathrm{cmH}_{2} \mathrm{O}: 45 \mathrm{cmH}_{2} \mathrm{O}$ (one patient), $50 \mathrm{cmH}_{2} \mathrm{O}$ (five patients), and $55 \mathrm{cmH}_{2} \mathrm{O}$ (seven patients).

In a preliminary, quantitative, $\mathrm{CT}$ analysis performed in the first 12 of our 51 patients, we observed $55 \%$ (IQR: 39 to 61) of non-aerated tissue at PEEP of 10 $\mathrm{CmH}_{2} \mathrm{O}$ before MRS. The non-aerated tissue decreased progressively to $23 \%$ (IQR: 15 to 35 ) after reaching plateau-pressures of $40 \mathrm{cmH}_{2} \mathrm{O}$ (at PEEP of $25 \mathrm{cmH}_{2} 0$ ), to
Table 3 Hemodynamic data before and after MRS

\begin{tabular}{ccc}
\hline & 24 $\mathbf{h}$ preceding MRS & First $\mathbf{2 4} \mathbf{h}$ after MRS \\
\hline MAP $(\mathrm{mmHg})$ & $82 \pm 9$ & $86 \pm 11$ \\
Arterial Lactate $(\mathrm{mg} / \mathrm{dL})$ & $16 \pm 10$ & $14 \pm 10$ \\
$\mathrm{ScVO}_{2}(\%)$ & $80 \pm 8$ & $85 \pm 10$ \\
Fluid Balance $(\mathrm{ml})$ & $4,050 \pm 2,724$ & $2,538 \pm 2,270$ \\
\hline
\end{tabular}

MAP, mean arterial pressure; lactate, arterial lactate; $\mathrm{ScvO}_{2}$, central venous saturation. Fluid balance, net fluid balance. Data expressed as mean \pm standard deviation.

10\% (IQR: 4 to 21\%) after reaching plateau-pressures of $50 \mathrm{cmH}_{2} \mathrm{O}$ (at PEEP of $35 \mathrm{cmH}_{2} 0$ ), and to 5\% (IQR: 2 to 10) after reaching plateau-pressures of $60 \mathrm{cmH}_{2} \mathrm{O}$ (at PEEP of $45 \mathrm{cmH}_{2} 0$ ). After PEEP titration (mean PEEP level of $23.7 \pm 2.3 \mathrm{cmH} 20$ ) the non-aerated tissue was kept at 7\% (IQR: 3 to 13) [33].

\section{CT analysis and the size of the potentially recruitable lung}

Fifty-one patients completed the visual assessment of recruitment by $\mathrm{CT}$, but only 45 patients had complete data for quantitative CT analysis. The amount of nonaerated tissue (percentage of lung mass) at minimum PEEP was 53.6\% (IQR: 42.5 to 62.4 ), which decreased to 8.7\% (IQR: 2.7 to 17.9 ) and $12.7 \%$ (IQR: 4.9 to 24.2 ) at maximum-PEEP and titrated-PEEP, respectively (Figure 2). Illustrative cases of MRS are depicted in Figure 3.

The histogram illustrating the size of the potentially recruitable lung in our sample is shown in Figure 4, with a median value of $45 \%$ (IQR: 25 to 53 ). Although there was correlation between the amount of non-aerated tissue at baseline and the potential for lung recruitment $\left(P<0.001, \mathrm{r}^{2}=0.54\right)$, the relative response to MRS was not correlated with the initial amount of nonaerated tissue $\left(P=0.24, \mathrm{r}^{2}=0.03\right)$.

\section{Gas exchange}

The response of the $\mathrm{PaO}_{2} / \mathrm{FIO}_{2}$ ratio to MRS is shown in Figure 5. Only seven patients did not reach a $\mathrm{PaO}_{2} /$

Table 2 Gas exchange and mechanical ventilation data before and throughout the first week after MRS

\begin{tabular}{|c|c|c|c|c|c|}
\hline & Before MRS & After MRS & Day 3 & Day 5 & Day 7 \\
\hline $\mathrm{PaO}_{2} / \mathrm{FiO}_{2}$ & $125 \pm 43$ & $302 \pm 102$ & $339 \pm 142$ & $345 \pm 110$ & $350 \pm 102$ \\
\hline $\mathrm{PaCO}_{2}(\mathrm{mmHg})$ & $48 \pm 13$ & $56 \pm 16$ & $52 \pm 13$ & $44 \pm 10$ & $42 \pm 9$ \\
\hline $\mathrm{pH}$ & $7.26 \pm 0.11$ & $7.20 \pm 0.12$ & $7.26 \pm 0.10$ & $7.37 \pm 0.09$ & $7.41 \pm 0.07$ \\
\hline $\mathrm{BE}$ & $-5.7 \pm 6.0$ & $-7.2 \pm 5.4$ & $-4.7 \pm 5.2$ & $-0.5 \pm 5.1$ & $1.7 \pm 4.1$ \\
\hline $\operatorname{PEEP}\left(\mathrm{cmH}_{2} \mathrm{O}\right)$ & $11.7 \pm 3.8$ & $24.6 \pm 2.9$ & $23.1 \pm 3.3$ & $19.5 \pm 4.3$ & $17.2 \pm 3.7$ \\
\hline Pplat $\left(\mathrm{cmH}_{2} \mathrm{O}\right)$ & $26.7 \pm 3.8$ & $39.9 \pm 4.3$ & $37.2 \pm 4.4$ & $32.8 \pm 6.8$ & $29.7 \pm 6.3$ \\
\hline$\Delta \mathrm{P}\left(\mathrm{cmH}_{2} \mathrm{O}\right)$ & $15 \pm 0$ & $15.4 \pm 3.4$ & $14.1 \pm 3.3$ & $13.3 \pm 4.6$ & $12.3 \pm 4.6$ \\
\hline $\mathrm{V}_{\mathrm{T}}(\mathrm{ml} / \mathrm{kg})$ & $-1-1-1$ & $6.9 \pm 1.4$ & $7.2 \pm 1.9$ & $8.6 \pm 1.8$ & $8.8 \pm 1.5$ \\
\hline $\mathrm{FiO}_{2}(\%)$ & 100 & $45 \pm 17$ & $41 \pm 18$ & $35 \pm 11$ & $37 \pm 16$ \\
\hline
\end{tabular}

$\Delta \mathrm{P}$, driving pressure; $\mathrm{BE}$, base excess; $\mathrm{FiO}_{2}$, oxygen inspiratory fraction; $\mathrm{PEEP}$, positive airway expiratory pressure; Pplat, plateau inspiratory pressure; $\mathrm{V}_{\mathrm{T}}$, tidal volume. Data expressed as mean \pm standard deviation 


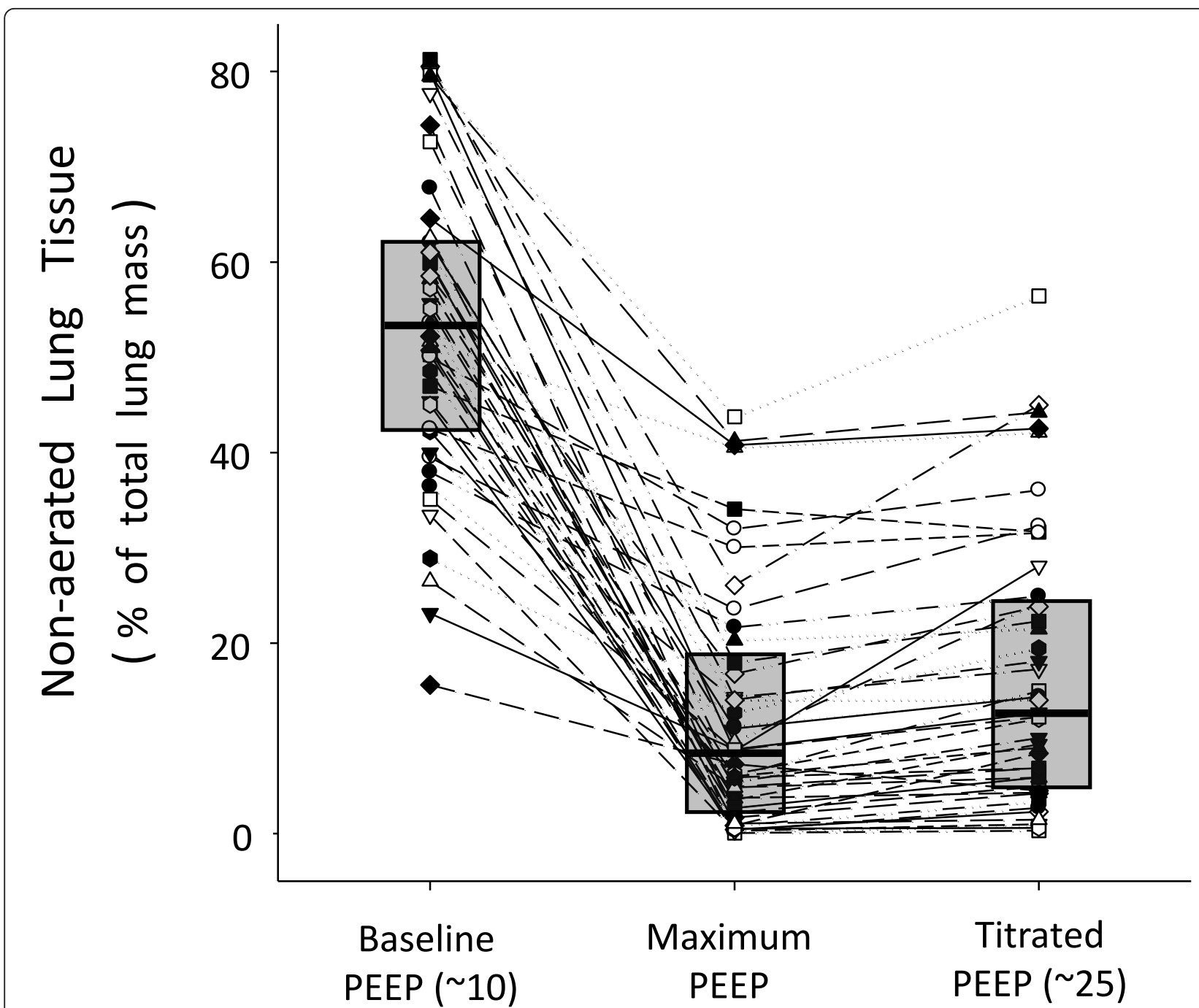

Figure 2 Amount of non-aerated tissue observed along the protocol. Numbers represent the percentage of non-aerated tissue (in relation to the total lung tissue) within the thick lung section ( 7 to $8 \mathrm{~cm}$ thick) from the carina to the diaphragm. Dashed lines represent the 45 individual cases and boxes represent the interquartile range, with a central line representing the median value at each moment.

$\mathrm{FIO}_{2}$ ratio $>200$ after MRS. The seven-day evolution of $\mathrm{PaO}_{2} / \mathrm{FIO}_{2}$ is shown in Figure 6. The $\mathrm{PaCO}_{2}$ and arterial $\mathrm{pH}$ seven-day evolution is shown in Table 2.

\section{Ventilation parameters after MRS}

After titration of PEEP, mean PEEP level was maintained at $24.6 \pm 2.9 \mathrm{cmH}_{2} \mathrm{O}$ and plateau-pressures at $40.0 \pm 4.3 \mathrm{~cm} \mathrm{H}_{2} \mathrm{O}$. According to the patients' evolution, PEEP and plateau-pressure progressively decreased to $17.2 \pm 3.7$ and $29.7 \pm 6.3$ respectively on Day 7 , while mean $\mathrm{PaO}_{2} / \mathrm{FIO}_{2}$ was kept above 300 (Figure 6).

\section{Evolution and outcome}

Forty patients were successfully weaned, of whom 27 were extubated after a median duration of mechanical ventilation of 9 (IQR: 7 to 13) days. Thirteen patients were tracheostomized. Length of ICU-stay and hospitalstay was 15 (IQR: 12 to 33) and 30 (IQR: 21 to 63) days, respectively. ICU mortality was $28 \%(14 / 51)$ and hospital mortality was $33 \%(17 / 51)$.

Mortality in our sample was not associated with a larger potential for lung recruitment $(P=0.33)$, nor with a larger mass of non-aerated tissue at baseline $(P=0.81)$. The APACHE score did not differ between survivors and non-survivors (19 \pm 8 versus $21 \pm 5$, respectively; $P$ $=0.29)$. From Day 1 to Day 7 , the SOFA score decreased significantly in the survival group (from $9 \pm 3$ to $4 \pm 4 ; P<0.001$ ), but not in the non-survival group (from $10 \pm 3$ to $10 \pm 4$ ). Non-survivors were older than survivors: $61 \pm 14$ versus $47 \pm 16$ years $(P=0.009)$.

During Day-1, the titrated PEEP and tidal-volumes were similar between survivors and non-survivors (24.6 


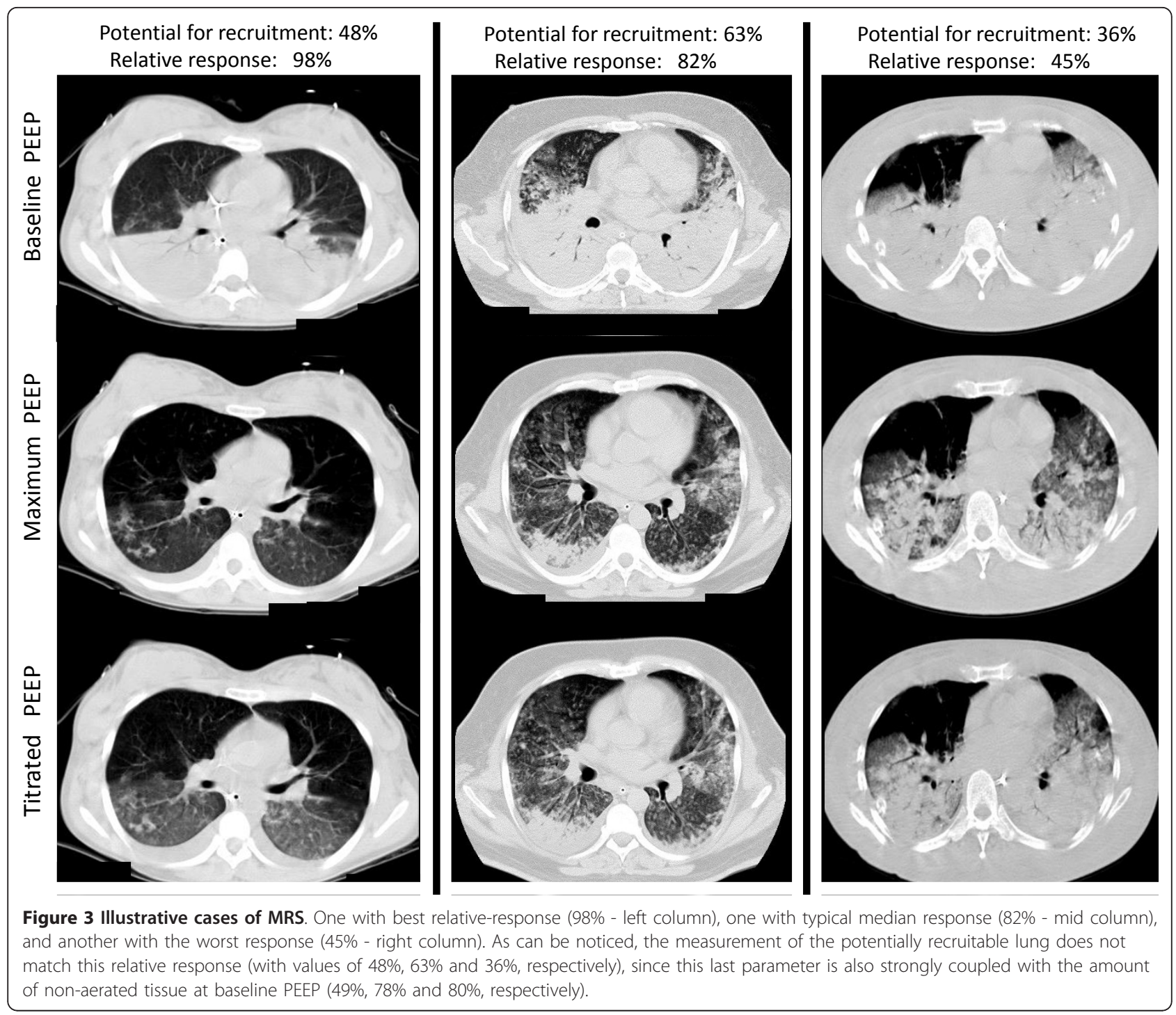

\pm 2.3 versus $24.8 \pm 4.1 \mathrm{cmH}_{2} 0 ; P=0.89$; and $6.9 \pm 1.3$ versus $6.8 \pm 1.7 \mathrm{~mL} / \mathrm{Kg} ; P=0.68)$, but Day-1 plateaupressures and Day-1 driving-pressures were higher in non-survivors when compared to survivors (43 \pm 6 versus $39 \pm 3 \mathrm{cmH}_{2} 0 ; P=0.039$; and $17.0 \pm 3.2$ versus 13.8 $\pm 2.6 \mathrm{cmH}_{2} 0 ; P=0.002$ ).

The $\mathrm{PaO}_{2} / \mathrm{FIO}_{2}$ ratio after MRS was higher in survivors versus non-survivors $(324 \pm 96$ versus $239 \pm 95.8$ mmHg; $P=0.015)$, but not the $\mathrm{PaCO}_{2}(53 \pm 16$ versus $62 \pm 17 \mathrm{mmHg} ; P=0.13$ ).

Cumulative fluid balance from entry till before MRS, or from entry till 24 hours after MRS was not different between survivors and non-survivors $(+2,314 \pm 1,988$ $\mathrm{mL}$ versus $+1,945 \pm 2,297 \mathrm{~mL} ; P=0.78$; or $3,715 \pm$ 2,863 versus $5,012 \pm 2,244 \mathrm{~mL} ; P=0.09$; respectively).

It is noteworthy that the multivariate logistic regression analysis revealed only two independent predictive factors for mortality: older age $(P=0.007)$ and higher inspiratory driving pressure (inspiratory delta pressurecontrol; $P=0.011$ ). Other variables tested in the multivariate model, which did not show significance were: Day-1 PEEP $(P=0.16)$, Day-1 plateau-pressure $(P=$ 0.17), Day-1 $\mathrm{PaCO}_{2}(P=0.44)$, Day-1 $\mathrm{FIO}_{2}(P=0.19)$, or Day- $1 \mathrm{PaO}_{2} / \mathrm{FIO}_{2}$ ratio $(P=0.31)$

\section{Side effects and complications}

There were no major complications secondary to transportation to the CT-room, or during MRS. Minor problems detected during transportation were: malfunctioning of infusion IV pumps with vasopressors (and consequent transitory hypotension), malfunctioning of transportation monitor, EKG electrodes and arterial pressure curves. One patient developed acute atrial fibrillation without hemodynamic instability, which was 


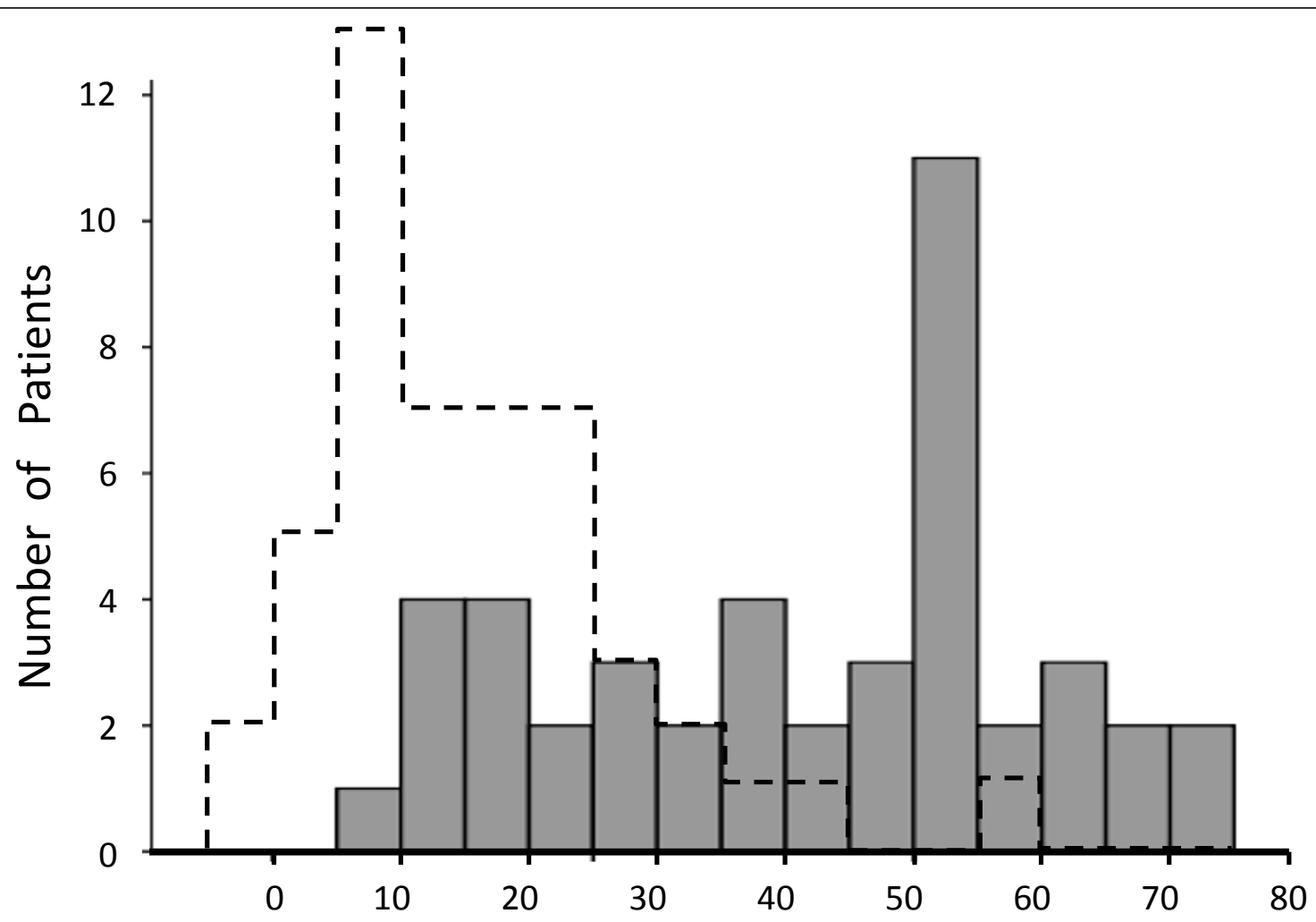

\section{Amount of Potentially Recruitable Lung (\% total lung weight)}

Figure 4 Histogram for the amount of potentially recruitable lung observed in our sample of patients $(\mathrm{N}=45)$. Dashed lines represent the equivalent histogram described by Gattinoni and cols. in a previous publication [29].

pharmacologically reversed. No barotrauma was detected during MRS in the CT-room, or immediately after transportation to the ICU. Transient decreases in arterial blood pressure occurred during MRS without need of interruption of the maneuver because of persistent hemodynamic instability. Pneumodiastinum was detected in two patients, but at more than $48 \mathrm{~h}$ after MRS. Both coincided with reduction in sedation and detection of patient-ventilator asynchrony by the investigators at bedside. After the detection of pneumomediastinum in the chest X-ray of these two patients, we only adjusted the patients' sedation, guaranteeing a better patient-ventilation synchrony. We did not change mechanical ventilation strategy and patients were kept following the pre-established protocol.

\section{Discussion}

The main findings of this study can be summarized as follows. MRS was a safe strategy to reduce the amount of non-aerated tissue in our non-selected population of severe ARDS patients. In order to obtain and sustain expressive recruitment, opening pressures above 45
$\mathrm{cmH}_{2} \mathrm{O}$ uninterruptedly followed by high PEEP were necessary, according to individual titration. By using MRS as a referential maneuver, the median percentage of potentially recruitable lung was $45 \%$, a considerable number when compared to previous studies [29], but a higher amount of non-aerated tissue at baseline did not predict a worse response. All CT-scans were analyzed after MRS and no signs of minor or major barotrauma were observed in any patient. No significant clinical complications associated with MRS were noted either.

Recently, Gattinoni and colleagues [29] found that ALI/ARDS patients with a higher mass of non-aerated tissue and a higher potentially recruitable lung had increased mortality. They also demonstrated that the potentially recruitable lung varied widely in their population with a mean value of $13 \pm 11 \%$ (considering the total lung mass). We believe that the main reason for the differences in relation to our study was the design of the recruitment maneuver per se: in Gattinoni's study [29], plateau inspiratory pressure was limited to 45 $\mathrm{cmH}_{2} \mathrm{O}$ and the associated PEEP was $5 \mathrm{cmH}_{2} \mathrm{O}$. Besides, 


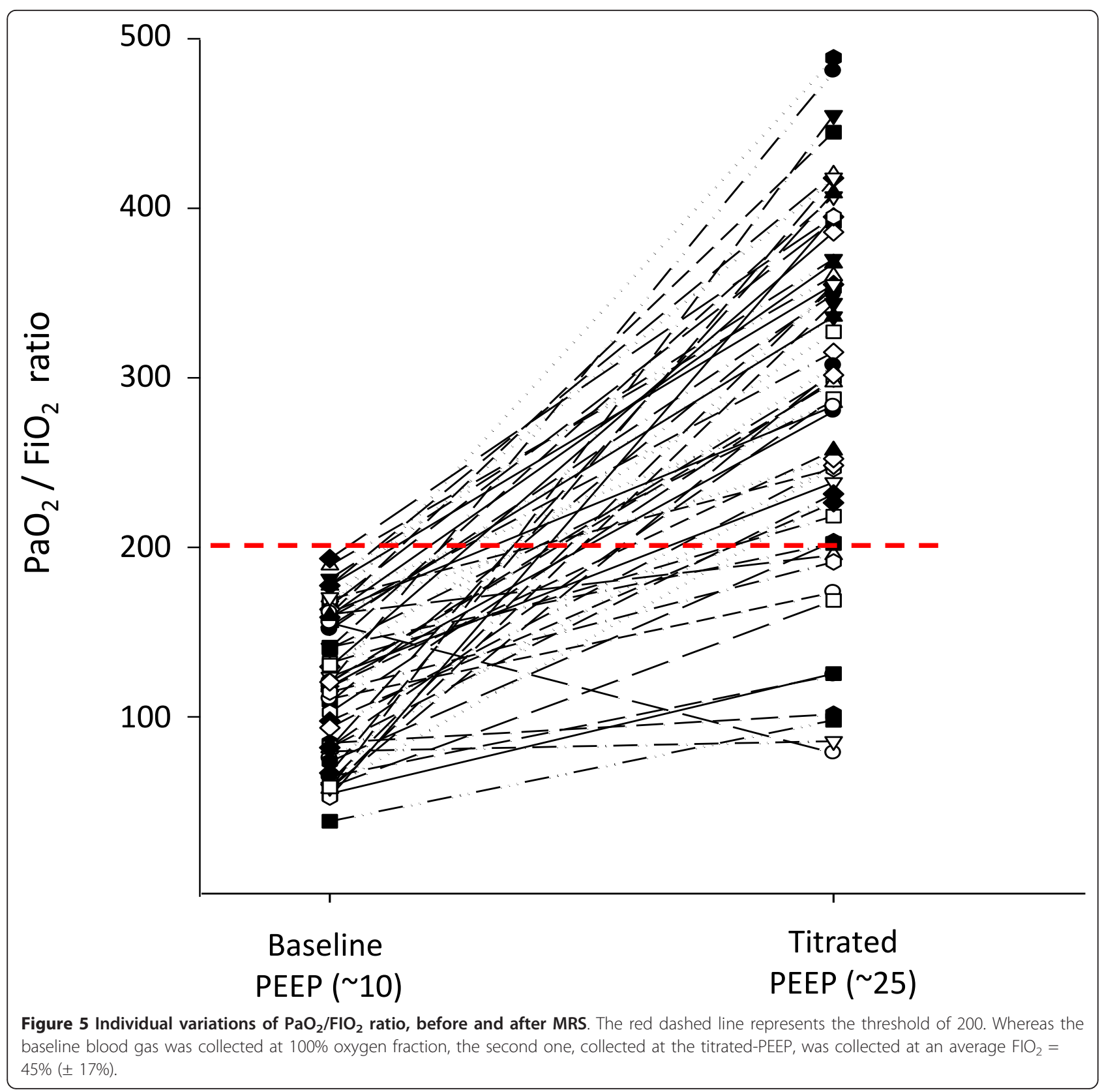

there may be important differences in the studied population, since the patients in Gattinoni' s study had a mean duration of invasive mechanical ventilation of $5 \pm$ 6 days when they were submitted to their recruitment protocol, while all our patients had less than 72 hours of ARDS onset. As demonstrated by Borges and colleagues [22], the maintenance of appropriate PEEP during the recruitment phase, above closing pressures (commonly above $15 \mathrm{cmH}_{2} \mathrm{O}$ ), is an essential component of recruitment maneuver, enhancing the recruitment effects of high plateau inspiratory pressures. Thus, the use of a low PEEP by Gattinoni and colleagues (5
$\mathrm{cmH}_{2} \mathrm{O}$ ) interposed during their "recruitment phase" probably counteracted the net efficacy of the maneuver, promoting cyclic de-recruitment during this critical phase. Additionally, previous studies and the present one suggest that a maximum recruiting pressure of 45 $\mathrm{cmH}_{2} \mathrm{O}$ was not enough to substantially re-aerate collapsed areas in severe ARDS [22,28,34]. In a preliminary CT analysis performed in 12 of our 51 patients, we observed the persistence of $22 \%$ of non-aerated tissue at airway pressures around $40 \mathrm{cmH}_{2} \mathrm{O}$ (accompanied by appropriate PEEP), in patients who later achieved less than $5 \%$ of lung collapse after MRS [33]. 


\section{Plateau Pressure, PEEP and $\mathrm{PaO} 2 / \mathrm{FIO} 2$}

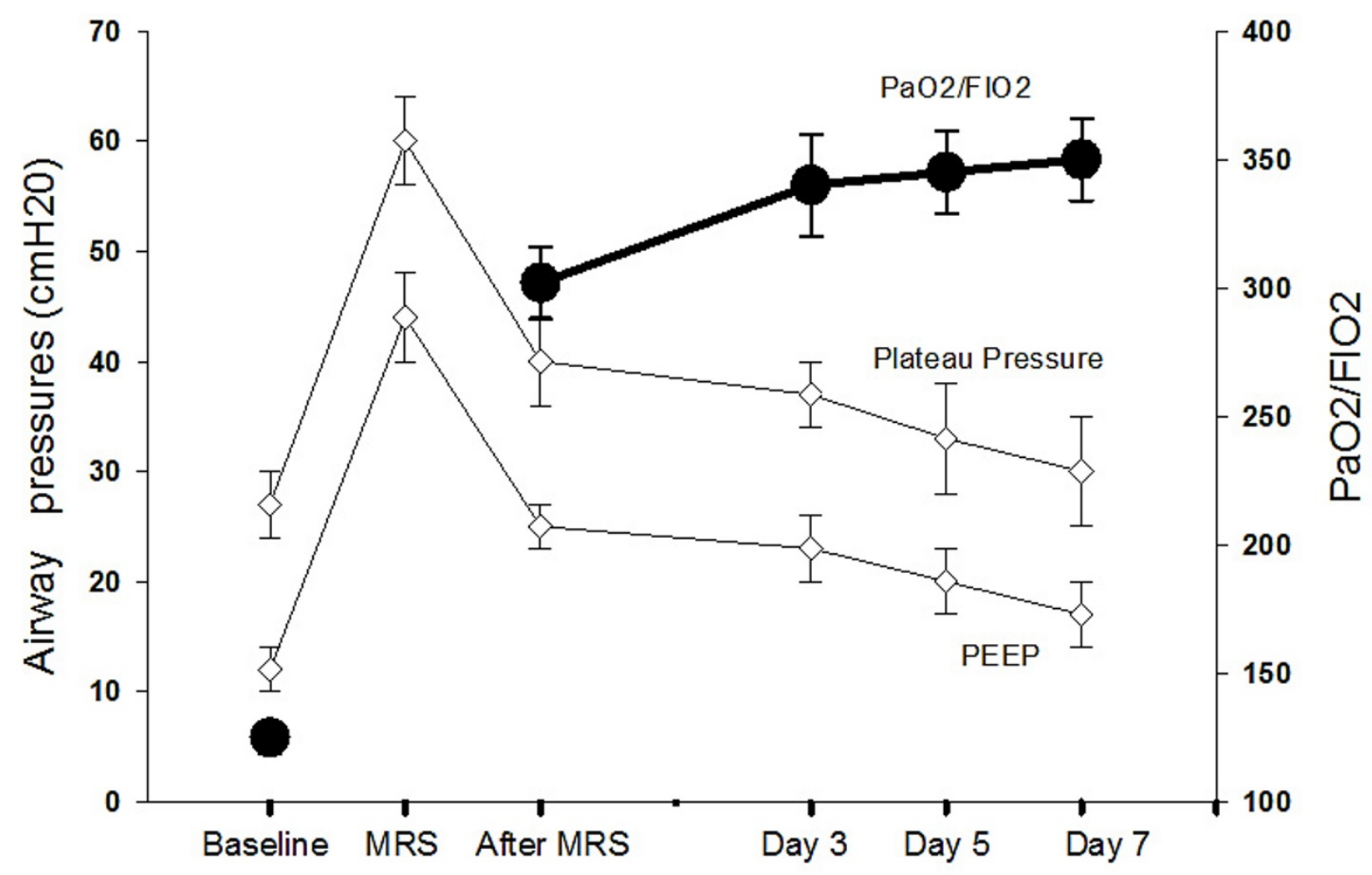

Figure 6 Evolution of $\mathrm{PaO}_{2} / \mathrm{FIO}_{2}$ ratio, plateau pressures and PEEP levels throughout seven days. Observe the relation among the variables before, during and throughout the seven days after MRS.

Our CT analysis revealed a four-fold reduction in the amount of non-aerated tissue after MRS (Figure 2), which means that the size of potentially recruitable lung in severe ARDS may be much higher (3.5 times) than previously reported [29,35] (Figure 4). Thus, the assumption that just a minority of patients with ARDS can be recruited $[29,36]$ must be reconsidered. It is worthy of note that every single patient presented some radiological response to MRS, and the relative response to the maneuver could not be predicted by the baseline $\mathrm{CT}$ evaluation. Although there was some correlation between the amount of non-aerated tissue at baseline and the potential for lung recruitment $\left(P<0.001, \mathrm{r}^{2}=\right.$ $0.54)$, the relative response to MRS was not correlated with the initial amount of non-aerated tissue $(P=0.24$, $\left.\mathrm{r}^{2}=0.03\right)$. Whereas the former, significant correlation likely reflects some mathematical coupling, that is, sicker patients have more room to improve, the latter, non- significant, correlation implies an important message: the initial CT quantification, even when showing impressive amounts of collapse, cannot rule out the chances of near-complete collapse reversal after MRS.

This interesting observation may explain why we did not find a correlation between mortality and the potential for lung recruitment in our patients, as previously reported by Gattinoni and Caironi [29,35]. If many of our patients with the highest potential for lung recruitment had near-complete reversal of collapse, the deleterious effects of lung collapse might have been especially counteracted in this subgroup.

Although the present study was designed to be a prospective case-series testing the MRS as described by Borges and colleagues [22], the two protocols were not identical. Some slight differences may explain the apparent higher recruitability of their patients, although the exact numbers are not provided in their publication. 
First, this case series had more strict inclusion criteria, but a less strict exclusion one. Thus, the present study included sicker patients, better representing the daily activities of a general ICU center. Secondly, the recruitment strategy in Borges' study had one additional recruitment step (CPAP of $40 \mathrm{cmH}_{2} 0$ for 40 seconds), with a longer duration of the intensive recruitment protocol: the total duration of their maneuver was $20 \mathrm{~min}$ utes (five steps of high inspiratory pressures, alternated with five steps of $25 \mathrm{cmH}_{2}$ O PEEP resting periods - each step with 2 minutes), as compared with a total duration of 8 minutes in the present study (four steps of progressive, high recruitment pressures, with 2 minutes at each step, and without resting periods in between).

The immediate response in terms of oxygenation revealed a large increment in $\mathrm{PaO}_{2} / \mathrm{FIO}_{2}$ (Figure 5), especially in the first few hours after MRS. The overall improvement in the $\mathrm{PaO}_{2} / \mathrm{FIO}_{2}$ ratio was higher than previously reported in recent trials [13-15,37] (Figure 6). As a counterpoint to some reports in the literature suggesting that the effects of a recruitment maneuver in ARDS are transitory $[38,39]$, our study showed that if PEEP is carefully selected after recruitment, the $\mathrm{PaO}_{2} /$ $\mathrm{FIO}_{2}$ ratio can be maintained at high levels $(>300)$ during the first few days (or weeks) of mechanical ventilation. This finding suggests the possibility of long term maintenance of an open lung status, throughout the course of invasive mechanical ventilation, at an acceptable clinical cost [22].

By following the CT guided strategy and trying to select the minimum PEEP to keep the lungs open, we were forced to apply high levels of plateau-inspiratory pressures to our patients (between 30 and $40 \mathrm{cmH}_{2} \mathrm{O}$ ), in spite of using relatively low-tidal volume ventilation ( 6 to $8 \mathrm{~mL} / \mathrm{kg}$ ). Such levels are higher than the ones recommended by some protective protocols $[13,14,40]$, and are certainly a matter of concern. We believe, however, that some of the findings in the present study, as well as in the recent literature, provide compelling arguments to counterbalance such concern. First of all, we did not find an important correlation between mortality and plateau-pressures in our study. This finding is in alignment with the results of some recent trials about PEEP selection, in which higher-PEEP arms consistently presented higher levels of plateau-inspiratory pressure [23] (especially in the Lung Open Ventilation Strategy (LOVS) study [15]), and yet, they resulted in similar or better outcome. Thus, the concerns about tidal hyperinflation or of excessive stress/strain [41,42] have always to be counterbalanced by the possibility of minimization of lung collapse with possible reduction of tidal-recruitment $[35,43,44]$. Secondly, overall mortality or barotrauma incidence in this study was comparable to the results of the best protective strategies reported in the literature $[12-15,23,40,45]$, despite the higher severity of disease in our case-series. And finally, we kept our focus on minimizing the delta inspiratory-pressures in our patients and, in fact, this variable was found to be the most important predictor of survival (besides age) in our population. In most patients, we could keep it below $15 \mathrm{~cm} \mathrm{H}_{2} \mathrm{O}$, a relatively safe value according to preliminary evidences $[46,47]$.

In retrospect, (maybe we could do better in terms of lung protection), trying to minimize further the deltainspiratory pressures and plateau-pressures after the MRS could have done better in terms of lung protection. Nevertheless, except for some few cases in which we could have accepted more permissive values of hypercapnia, or could have optimized $\mathrm{CO} 2$ removal [48], the main constraints found during the realization of this protocol were related to $\mathrm{PaCO}_{2}$ levels, which averaged $56( \pm 16 \mathrm{mmHg})$ during the first 24 hours after mechanical ventilation (resulting in a $\mathrm{pH}$ around approximately 7.20), and also related to the need of high PEEP levels, sustained along days after the MRS. In practice, we did not reduce PEEP before the first 48 hours, otherwise we would have had to increase the $\mathrm{FIO}_{2}$ (to $>40 \%$ ), a procedure that we tried to avoid by protocol design.

Recently, Terragni and colleagues [41] showed that ventilation with tidal volumes around $6 \mathrm{ml} / \mathrm{kg}$ and "protective" plateau pressure (less than $30 \mathrm{cmH}_{2} \mathrm{O}$ ) were not enough to prevent what the authors defined as "tidal hyperinflation" in ARDS patients, especially in those patients with large amounts of non-aerated tissue at the dependent lung zones. The authors' conclusion was that collapse was an unavoidable phenomenon during ARDS, promoting the heterogeneity of tidal ventilation and hyperinflation of the baby lung, despite low tidal-volume ventilation. The authors suggested that the only possible strategy to prevent harm was the further decrease of airway pressures, even at the expense of deterioration in blood gases. Since this strategy is unfeasible in many patients, especially in those with severe hypoxemia, our study suggests that an alternative strategy is conceivable. MRS was particularly effective in those patients presenting larger amounts of collapse at baseline. Although not specifically tested in this study, the subsequent reversal of collapse might promote a more homogeneous distribution of tidal ventilation, making use of the previously collapsed parenchyma to "share" the tidal volume, and possibly relieving nondependent lung hyperinflation described by Terragni and colleagues [41]. This hypothesis was already suggested by others $[22,34,49]$. It is worthy of mention that in a detailed CT analysis performed in the first 12 ARDS patients of our protocol, the overall amount of tidal hyperinflated tissue increased by only $1 \%( \pm 1 \%)$ after MRS, despite a large increase in 
PEEP from baseline (approximately $10 \mathrm{cmH}_{2} \mathrm{O}$ ) to the titrated PEEP (approximately $25 \mathrm{cmH}_{2} \mathrm{O}$ ) [33].

Recently, Talmor and colleagues [37] monitored esophageal pressure in ARDS patients and observed that even with PEEP levels around $18 \mathrm{cmH}_{2} \mathrm{O}$ and plateau pressures above $30 \mathrm{cmH}_{2} \mathrm{O}$, transpulmonary inspiratory pressures were kept below reasonable levels $(<12$ $\mathrm{cmH}_{2} \mathrm{O}$ ). They also showed that in order to keep the lung open, with transpulmonary expiratory pressures above zero, PEEP had to be kept above $15 \mathrm{cmH}_{2} \mathrm{O}$. Similarly, many of our patients were ventilated with plateau pressures above $30 \mathrm{cmH}_{2} \mathrm{O}$ and PEEP levels above 15 $\mathrm{cmH}_{2} \mathrm{O}$ during the first days of ARDS, but with driving pressures less than $15 \mathrm{cmH}_{2} \mathrm{O}$, as in Talmor's study [37].

\section{Limitations of the study}

We could not scan the whole lung due to time constraints and radiation exposure, so we chose to limit CT images to a representative lung fraction, from the carina to the diaphragm. Although not representing the whole lung behavior, previous studies strongly suggested that such partial sampling is adequate for quantitative CT analysis [50].

In this case series we performed inspiratory/expiratory thoracic CT scans only in the first 12 patients. Having found an increment of inspiratory hyperdistension as small as $1 \%$ at a PEEP of $25 \mathrm{cmH} 20$ after the MRS (when compared to a PEEP of $10 \mathrm{cmH}_{2} \mathrm{O}$ before MRS), we decided to limit the exposure to radiation, performing only expiratory images during MRS in the remaining 39 patients.

Few unstable, critically ill patients and some obese and complicated abdominal post-operative patients could not be transported to the CT facility and were not included in our study (18 out of 69 ). Thus, our non-selective sample of ARDS patients has to be put into perspective.

Although our ICU and hospital mortality was relatively low ( 28 and $33 \%$, respectively), this case series was not designed to estimate long term mortality, limiting the conclusion to be drawn about the ultimate clinical benefit of MRS. The fact that the SOFA score did not decrease in the non-survival patients indicates that in this specific population a non-detectable factor perpetuated multiple organ failure and patients' death despite MRS.

By using echocardiography, Vieillard-Baron and colleagues [51] demonstrated the occurrence of acute corpulmonale in about $25 \%$ of their ARDS patients submitted to limited pressure ventilation (average PEEP $7 \pm 3$ $\mathrm{cmH}_{2} \mathrm{O}$ ). In our study, we did not monitor the patients systematically with echocardiography. Nevertheless, even using much higher ventilatory pressures than in the above mentioned study, there was no clinical evidence of acute right ventricular failure, systemic refractory shock or interruption of MRS due to acute hemodynamic complications.

\section{Conclusion}

In our severe ARDS patients with multiple organ failure, MRS was a safe strategy to reverse non-aerated lung parenchyma and hypoxemia in most of them, for extended periods of time. In this particular study, CT was instrumental to individualize the strategy, in order to achieve almost full recruitment and to titrate PEEP, keeping the lungs open. Our results indicate that the general principles of the MRS are a valid alternative to conventional ventilation, worth being tested in future randomized trials.

\section{Key messages}

- The MRS was feasible and reversed hypoxemia and the non-aerated areas of the lungs for extended periods of time in 51 patients with early, severe ARDS, revealing a much larger lung recruitability than reported in previous studies.

- The response to MRS cannot be predicted a priori and has to be tested individually. The initial CT quantification, even when showing impressive amounts of collapse, cannot rule out the chances of near-complete collapse reversal.

- Hospital mortality in our case-series was associated with older age and higher driving inspiratory pressures, but not with higher plateau-pressures, nor with a larger potential for lung recruitment at baseline.

- During MRS, we did not observe barotrauma or significant clinical complications.

- MRS should be tested in a randomized, prospective, controlled, clinical trial.

\section{Abbreviations}

APACHE II: Acute Physiology and Chronic Health Evaluation II; ARDS: Acute Respiratory Distress Syndrome; CT: computed tomography; EKG: electrocardiogram; $\mathrm{FIO}_{2}$ : inspiratory oxygen fraction of oxygen; $\mathrm{HU}$ : Hounsfield Unit; IQR: interquartile range; MAP: mean arterial pressure; MRS: Maximum Recruitment Strategy; NPOF: non-pulmonary organ failure; PEEP: positive end expiratory pressure; $P_{\text {closing: }}$ minimum expiratory pressure to sustain recruitment; $P_{\text {opening }}$ : minimum inspiratory pressure to achieve recruitment; PxV curve: pressure $\times$ volume curve; ROI: region of interest; $\mathrm{S}_{\mathrm{CVO}}$ : central venous saturation; SD: standard deviation; SOFA: Sequential Organ Failure Assessment; $\mathrm{SpO}_{2}$ : pulse oxygen saturation; VILI: ventilator induced lung injury; VT: tidal volume.

\section{Acknowledgements}

We sincerely thank all the Albert Einstein's adult ICU residents, nurses and respiratory therapists, and the Albert Einstein's transport and radiology team for all their effort and help in conducting this protocol. We also thank Ms. Adriana Pardini for reviewing the manuscript.

\section{Author details}

${ }^{1}$ Adult ICU Hospital Israelita Albert Einstein, São Paulo, 05652-000, Brazil.

${ }^{2}$ Radiology Department, Hospital Israelita Albert Einstein, São Paulo, 05652000, Brazil. ${ }^{3}$ Respiratory ICU, Hospital das Clínicas and LIM-09, University of 
São Paulo, Brazil. ${ }^{4}$ Department of Surgical Sciences, Section of Anaesthesiology \& Critical Care, Uppsala University, SE-751 85, Uppsala, Sweden.

\section{Authors' contributions}

GFJM, CSVB, FS, REC, MF, RA and RHP participated in transportation and care of the patients included during the protocol. GFJM and DCBS performed quantitative CT analysis. GFJM, JBB, MBPA and CSVB participated in the design and coordination of the protocol and in the drafting of the manuscript. All authors read and approved the final manuscript.

\section{Competing interests}

The authors declare that they have no competing interests.

Received: 26 May 2011 Revised: 30 October 2011

Accepted: 8 January 2012 Published: 8 January 2012

\section{References}

1. Blank R, Napolitano LM: Epidemiology of ARDS and ALI. Crit Care Clin 2011, 27:439-458.

2. Webb HH, Tierney DF: Experimental pulmonary edema due to intermittent positive pressure ventilation with high inflation pressures. Protection by positive end-expiratory pressure. Am Rev Respir Dis 1974, 110:556-565.

3. Dreyfuss D, Saumon G: Ventilator-induced injury. In Principles and Practice of Mechanical Ventilation. Edited by: Tobin MJ. New York: McGraw-Hill, Inc; 1994:793-811.

4. Frank JA, Yumiko I, Slutsky AS: Pathogenesis of ventilator-induced lung injury. In Acute Respiratory Distress Syndrome. Volume 179. Edited by: Matthay M. Marcel Dekker. Boca Raton, FL: CRC Press; 2003:201-244, [Lenfant C (Series Editor) Lung Biology in Health and Disease].

5. Dreyfuss D, Saumon G: Role of tidal volume, FRC, and end-inspiratory volume in the development of pulmonary edema following mechanical ventilation. Am Rev Respir Dis 1993, 148:1194-1203.

6. Ranieri VM, Suter PM, Tortorella C, De Tullio R, Dayer JM, Brienza A, Bruno F, Slutsky AS: Effect of mechanical ventilation on inflammatory mediators in patients with acute respiratory distress syndrome: a randomized controlled trial. JAMA 1999, 282:54-61.

7. Dreyfuss D, Saumon G: Ventilator-induced lung injury: lessons from experimental studies. Am J Respir Crit Care Med 1998, 157:294-323.

8. Tremblay L, Valenza F, Ribeiro SP, Li J, Slutsky AS: Injurious ventilatory strategies increase cytokines and c-fos m-RNA expression in an isolated rat lung model. J Clin Invest 1997, 99:944-952.

9. Santos CC, Zhang H, Liu M, Slutsky AS: Bench-to-bedside review: biotrauma and modulation of the innate immune response. Crit Care 2005, 9:280-286

10. Parker JC, Hernandez LA, Peevy KJ: Mechanisms of ventilator-induced lung injury. Crit Care Med 1993, 21:131-143.

11. Amato MBP, Barbas CSV, Carvalho CRR: Protective ventilation for the acute respiratory distress syndrome. N Engl J Med 1998, 339:196-199.

12. Villar J, Kacmarek RM, Perez-Mendez L, Aguirre-Jaime A: A high positive end-expiratory pressure, low tidal volume ventilatory strategy improves outcome in persistent acute respiratory distress syndrome: a randomized, controlled trial. Crit Care Med 2006, 34:1311-1318.

13. Brower RG, Lanken PN, MacIntyre N, Matthay MA, Morris A, Ancukiewicz M, Schoenfeld D, Thompson BT: Higher versus lower positive end-expiratory pressures in patients with the acute respiratory distress syndrome. $\mathrm{N}$ Engl J Med 2004, 351:327-336.

14. Mercat A, Richard JC, Vielle B, Jaber S, Osman D, Diehl JL, Lefrant JY, Prat G, Richecoeur J, Nieszkowska A, Gervais C, Baudot J, Bouadma L, Brochard L, Expiratory Pressure (Express) Study Group: Positive end-expiratory pressure setting in adults with acute lung injury and acute respiratory distress syndrome: a randomized controlled trial. JAMA 2008, 299:646-655.

15. Meade MO, Cook DJ, Guyatt GH, Slutsky AS, Arabi YM, Cooper DJ, Davies AR, Hand LE, Zhou Q, Thabane L, Austin P, Lapinsky S, Baxter A, Russell J, Skrobik Y, Ronco JJ, Stewart TE, Lung Open Ventilation Study Investigators: Ventilation strategy using low tidal volumes, recruitment maneuvers, and high positive end-expiratory pressure for acute lung injury and acute respiratory distress syndrome: a randomized controlled trial. JAMA 2008, 299:637-645.
16. Gattinoni L, Caironi P, Carlesso E: How to ventilate patients with acute lung injury and acute respiratory distress syndrome. Curr Opin Crit Care 2005, 11:69-76.

17. Gattinoni L, Vagginelli F, Chiumello D, Taccone P, Carlesso E: Physiologic rationale for ventilator setting in acute lung injury/acute respiratory distress syndrome patients. Crit Care Med 2003, 31:5300-304.

18. Marini JJ, Gattinoni L: Ventilatory management of acute respiratory distress syndrome: a consensus of two. Crit Care Med 2004, 32:250-255.

19. Richards GA, Hopley M, Kacmarek RM, Fujino Y, Amato M: Successful recruitment. Crit Care Med 2002, 30:2169, author reply 2169-2170.

20. Fujino Y, Goddon S, Dolhnikoff M, Hess D, Amato MB, Kacmarek RM: Repetitive high-pressure recruitment maneuvers required to maximally recruit lung in a sheep model of acute respiratory distress syndrome. Crit Care Med 2001, 29:1579-1586.

21. Girgis $K$, Hamed $H$, Khater $Y$, Kacmarek RM: A decremental PEEP trial identifies the PEEP level that maintains oxygenation after lung recruitment. Respir Care 2006, 51:1132-1139.

22. Borges JB, Okamoto VN, Matos GF, Caramez MP, Arantes PR, Barros F, Souza CE, Victorino JA, Kacmarek RM, Barbas CS, Carvalho CR, Amato MB: Reversibility of lung collapse and hypoxemia in early acute respiratory distress syndrome. Am J Respir Crit Care Med 2006, 174:268-278.

23. Briel M, Meade M, Mercat A, Brower RG, Talmor D, Walter SD, Slutsky AS, Pullenayegum E, Zhou Q, Cook D, Brochard L, Richard JC, Lamontagne F, Bhatnagar N, Stewart TE, Guyatt G: Higher vs lower positive endexpiratory pressure in patients with acute lung injury and acute respiratory distress syndrome: systematic review and meta-analysis. JAMA 2010, 303:865-873.

24. Bohm SH, Vazquez de Anda GF, Lachmann B: The open lung concept. In Yearbook of Intensive Care and Emergency Medicine. Edited by: Vincent J-L. Berlin: Springer Verlag; 1998:430-440.

25. Lachmann B: Open up the lung and keep the lung open. Intensive Care Med 1992, 18:319-321.

26. Barbas CS, de Matos GF, Pincelli MP, da Rosa Borges E, Antunes T, de Barros JM, Okamoto V, Borges JB, Amato MB, de Carvalho CR: Mechanical ventilation in acute respiratory failure: recruitment and high positive end-expiratory pressure are necessary. Curr Opin Crit Care 2005, 11:18-28.

27. Papadakos PJ, Lachmann B: The open lung concept of mechanical ventilation: the role of recruitment and stabilization. Crit Care Clin 2007, 23:241-250, ix-X.

28. Borges JB, Carvalho CR, Amato MB: Lung recruitment in patients with ARDS. N Engl J Med 2006, 355:319-320, author reply 321-312.

29. Gattinoni L, Caironi P, Cressoni M, Chiumello D, Ranieri VM, Quintel M, Russo S, Patroniti N, Cornejo R, Bugedo G: Lung recruitment in patients with the acute respiratory distress syndrome. N Engl J Med 2006, 354:1775-1786.

30. Michard F, Boussat S, Chemla D, Anguel N, Mercat A, Lecarpentier Y, Richard C, Pinsky MR, Teboul J-L: Relation between respiratory changes in arterial pulse pressure and fluid responsiveness in septic patients with acute circulatory failure. Am J Respir Crit Care Med 2000, 162:134-138.

31. Michard F, Chemla D, Richard C, Wysocki M, Pinsky Michael R, Lecarpentier $Y$, Teboul J-L: Clinical use of respiratory changes in arterial pulse pressure to monitor the hemodynamic effects of PEEP. Am J Respir Crit Care Med 1999, 159:935-939.

32. De Backer D, Heenen S, Piagnerelli M, Koch M, Vincent JL: Pulse pressure variations to predict fluid responsiveness: influence of tidal volume. Intensive Care Med 2005, 31:517-523

33. Matos GFJ, Borges JB, Amato MBP, Barbas CSV: Maximum recruitment strategy minimizes tida-recruitment in severe ARDS: a CT scan study. Critical Care 2010, 14(Suppl.1):P186.

34. Schreiter D, Reske A, Stichert B, Seiwerts M, Bohm SH, Kloeppel R, Josten C: Alveolar recruitment in combination with sufficient positive endexpiratory pressure increases oxygenation and lung aeration in patients with severe chest trauma. Crit Care Med 2004, 32:968-975.

35. Caironi P, Cressoni M, Chiumello D, Ranieri M, Quintel M, Russo SG, Cornejo R, Bugedo G, Carlesso E, Russo R, Caspani L, Gattinoni L: Lung opening and closing during ventilation of acute respiratory distress syndrome. Am J Respir Crit Care Med 2010, 181:578-586.

36. D'Angelo E, Calderini E, Robatto FM, Puccio P, Milic-Emili J: Lung and chest wall mechanics in patients with acquired immunodeficiency syndrome and severe Pneumocystis carinii pneumonia. Eur Respir J 1997, 10:2343-2350. 
37. Talmor D, Sarge T, Malhotra A, O'Donnell CR, Ritz R, Lisbon A, Novack V Loring $\mathrm{SH}$ : Mechanical ventilation guided by esophageal pressure in acute lung injury. N Engl J Med 2008, 359:2095-2104.

38. Villagra A, Ochagavia A, Vatua S, Murias G, Del Mar Fernandez M, Lopez Aguilar J, Fernandez R, Blanch L: Recruitment maneuvers during lung protective ventilation in acute respiratory distress syndrome. Am J Respir Crit Care Med 2002, 165:165-170.

39. Blanch L, Fernandez R, Lopez-Aguilar J: Recruitment maneuvers in acute lung injury. Respir Care Clin N Am 2002, 8:281-294.

40. ARDSNet: Ventilation with lower tidal volumes as compared with traditional tidal volumes for acute lung injury and the acute respiratory distress syndrome. N Engl J Med 2000, 342:1301-1308.

41. Terragni PP, Rosboch G, Tealdi A, Corno E, Menaldo E, Davini O, Gandini G, Herrmann P, Mascia L, Quintel M, Slutsky AS, Gattinoni L, Ranieri VM: Tidal hyperinflation during low tidal volume ventilation in acute respiratory distress syndrome. Am J Respir Crit Care Med 2007, 175:160-166.

42. Chiumello D, Carlesso E, Cadringher P, Caironi P, Valenza F, Polli F, Tallarini F, Cozzi P, Cressoni M, Colombo A, Marini JJ, Gattinoni L: Lung stress and strain during mechanical ventilation for acute respiratory distress syndrome. Am J Respir Crit Care Med 2008, 178:346-355.

43. Muscedere JG, Mullen JB, Gan K, Slutsky AS: Tidal ventilation at low airway pressures can augment lung injury. Am J Respir Crit Care Med 1994, 149:1327-1334.

44. Suh GY, Koh Y, Chung MP, An CH, Kim H, Jang WY, Han J, Kwon OJ: Repeated derecruitments accentuate lung injury during mechanical ventilation. Crit Care Med 2002, 30:1848-1853.

45. Villar J, Blanco J, Añón JM, Santos-Bouza A, Blanch L, Ambrós A, Gandía F, Carriedo D, Mosteiro F, Basaldúa S, Fernández RL, Kacmarek RM, ALIEN Network: The ALIEN study: incidence and outcome of acute respiratory distress syndrome in the era of lung protective ventilation. Intensive Care Med 2011, 37:1932-1941.

46. Amato MBP, Barbas CSV, Pastore L, Grunauer MA, Magaldi RB, Carvalho CRR: Minimizing barotrauma in ARDS: protective effects of PEEP and the hazards of driving and plateau pressures. Am J Respir Crit Care Med 1996, 153:A375.

47. Estenssoro E, Dubin A, Laffaire E, Canales H, Saenz G, Moseinco M, Pozo M, Gomez A, Baredes N, Jannello G, Osatnik J: Incidence, clinical course, and outcome in 217 patients with acute respiratory distress syndrome. Crit Care Med 2002, 30:2450-2456.

48. Amato MBP: Permissive hypercapnia. In Acute Lung Injury. Volume 30 Edited by: Marini JJ, Evans TW. Berlin, Heidelberg, New York: SpringerVerlag; 1997:258-275, Vincent JL (Series Editor) Update in Intensive Care and Emergency Medicine].

49. Egan EA: Lung inflation, lung solute permeability, and alveolar edema. J Appl Physiol 1982, 53:121-125.

50. Gattinoni L, Caironi P, Pelosi P, Goodman LR: What has computed tomography taught us about the acute respiratory distress syndrome? Am J Respir Crit Care Med 2001, 164:1701-1711.

51. Vieillard-Baron A, Schmitt JM, Augarde R, Fellahi JL, Prin S, Page B, Beauchet A, Jardin F: Acute cor pulmonale in acute respiratory distress syndrome submitted to protective ventilation: clinical implications and prognosis. Crit Care Med 2001, 29:1551-1555, Erratum in Crit Care Med 2002, 30:726.

\section{doi:10.1186/cc10602}

Cite this article as: de Matos et al: How large is the lung recruitability in early acute respiratory distress syndrome: a prospective case series of patients monitored by computed tomography. Critical Care 2012 16: R4.

\section{Submit your next manuscript to BioMed Central and take full advantage of:}

- Convenient online submission

- Thorough peer review

- No space constraints or color figure charges

- Immediate publication on acceptance

- Inclusion in PubMed, CAS, Scopus and Google Scholar

- Research which is freely available for redistribution 